\title{
Parental Influences on the High School Students' Academic Achievement: A Comparison of Asian Immigrants, Asian Americans, and White Americans
}

Wei-Cheng Mau

\begin{abstract}
This study investigates the differences in parental influence on academic achievement of Asian immigrants, Asian Americans, and White Americans. The sample consisted of a nationally representative sample of 10th grade students obtained from the National Educational Longitudinal Study of 88, first follow-up, sponsored by the National Center for Educational Statistics. Results indicate that both Asian immigrants and Asian Americans spent significantly more time on homework and perceived higher parental educational expectation than did White American students. White American students, on the other hand, reported more parental involvement in school activities. A negative relationship between parental involvement and academic achievement was found for the Asian immigrant and Asian American students. Implications of the findings on academic achievement are discussed based on cultural perspectives.
\end{abstract}

The educational success of Asian countries, especially in the area of mathematics, has promoted many discussions and continuing interest among researchers (Baker, 1993; Beardsley, 1992; Cipra, 1993; Stedman, 1994; Stevenson, 1992; Stevenson, Chen, \& Lee, 1993; Stevenson \& Stigler, 1992; Westbury, 1992, 1993; also see discussions by Mayer, Tajika, \& Stanley, 1991; Mayer \& Tajika, 1993; Stigler \& Miller, 1993; Sue \& Okazaki, 1990). Not only are the students in Asian countries superior in educational achievement, Asian students in the United States, under similar educational environment, also perform at a higher level than White American students (American College Testing, 1989; College Board, 1989). Indeed, recent studies comparing Asian American students and White American students seemed to support these contentions (Mau, 1995; Peng \& Hill, 1995). This seems to suggest that cultural upbringing may be a strong factor contributing to the educational success of both Asian students in Asian countries as well as in the United States.

Asian Americans are one of the fastest growing minority groups in the United States and are primarily comprised of foreign-born immigrants. Intra-group differences among the Asian American population are vast. This study attempted to examine both the intra-group and between-group differences in educational effort, perceived parental expectation, and parental educational involvement and their effects on academic achievement.

\section{Educational Effort}

It is a prevalent belief in Asian culture that a deficiency can be overcome with diligence; this belief is considered to be a major contributing factor to success (Chang, 1985). This attitude stems from Confucian beliefs about the role of effort in achievement, which has been emphasized in Chinese writings and is found in Japanese philosophy (Stevenson, 1992).

In a recent report from the National Center for Educational Statistics, Green, Dugoni, Ingels, and Camburn, (1995) indicated that students who spent more time on homework performed better than their peers who spent less time. Student effort and time on task may be considered as more of a direct determinant of student achievement. One of the values transmitted to Asian children is manifested in children's school endeavors. Several studies of immigrants have documented the cultural differences in beliefs about children's academic performance. For example, Hess, Chang, and McDevitt (1987) indicated that mothers in the People's Republic of China viewed lack of effort as the major cause of low 
performance. Chinese-American students also believed lack of effort as important but attributed to other causes, whereas White American students attribute responsibility for academic achievement more evenly across the causes. In another study, Yan and Gaier (1994) found that American students attributed academic achievement more often to ability than did Asian students.

When parents believe success in school depends for the most part on effort rather than ability, they are more likely to encourage hard work and participation in activities related to academic achievement. The fact that Asian students spend more time on school work and considerably less time in non-school related activities than White Americans and other racial/ethnic groups seems to reflect this cultural value (Stevenson, Lee, \& Stigler, 1986). The success stories of Asian Americans validates the assumption that such values were present in the families of early immigrants and were pre-served over several generations, although these values may decline over time (Hess, Chang, \& McDevitt, 1987).

\section{Parental Educational Expectation}

Parental educational expectation is another motivational/cultural factor that has a direct relationship with students' school performance. Studies have shown that parental educational expectation is generally associated with students' academic performance (Hess \& Holloway, 1984; Hewison \& Tizard, 1980; Kerckhoff, 1989; Peng \& Hill, 1995; Scott-Jones, 1984; Smith, 1991). The degree of parental expectation which is perceived by students differs between cultural/ethnic groups and has a direct impact on children's academic performance (Mau, 1995). Because of the emphasis on education and efforts in Asian culture, it is reasonable to believe that Asian students are likely to perceive a higher level of parental educational expectation than are White Americans.

\section{Parental Educational Involvement}

Parental influence can also transpire in parents' involvement in their children's educational activities. For years research has demonstrated that parental involvement is one of the key factors of success in school. Studies have shown that parental involvement providing support, encouragement, and direct instruction in the home, as well as maintaining good communications with the school, has improved younger students' school performance. For example, Epstein (1985) in a longitudinal study of 3003 rd and 5 th grade students showed that students whose teachers were leaders in the use of parental involvement made greater gains in reading achievement than did students whose teachers were not recognized for encouraging parental involvement. Hewison and Tizard (1980) found that children encouraged to read to their parents, and to talk with their parents about their reading, had markedly higher reading gains than children who did not have the opportunity.

Although the effect of parental influence on younger students' academic achievement has been well documented, little is known about what effect this influence has on older students. The cultural/racial difference in parental influence has not been fully examined. Is there a difference in parental expectation and educational involvement between Asian American students and White American students? How does acculturation affect academic practice? Are there differences between recent immigrants and established immigrants regarding parental involvement and students' school practice? Does academic effort and perceived educational expectation decrease as Asian students become more acculturated?

Acculturation, defined as a process of integration with and differentiation from the dominant culture, is considered to be one of the most important variables in understanding intra-group differences (Atkinson, 1983; Cuellar, Harris, \& Jasso, 1980; Sodowsky, Lai, \& Plake, 1991). Acculturation takes place when an individual begins to interact with the dominant culture, and often results in adaptation of the value system of the dominant culture (Social Science Research Council, 1954). Fong (1973) indicated that parental authority decreased as Chinese Americans became more acculturated. Sodowsky, Lai, and Plake (1991) examined the moderating effect of sociocultural variables on acculturation attitudes of Asian and Hispanic Americans, indicating that first-generation immigrants used less English and were less 
acculturated than the second, third, and fourth generations. In this study, language (whether English is the native language or the second language) was used as the acculturation construct which differentiated between recent Asian immigrants and established Asian immigrants.

The purpose of this study was to compare recent Asian immigrants (English as second language), acculturated Asian Americans (English as native language) and White Americans regarding their perceived parental educational expectation, parental educational involvement, educational endeavors, and academic achievement. The relative importance of motivational and cultural variables in predicting educational achievement of high school students was also examined. The findings of this study may provide some insight for school personnel and researchers regarding the acculturation process in relation to students' academic endeavors, parental involvement, and their education-al outcomes.

\section{Method}

One of the major criticisms of comparison studies on achievement is sampling bias such as differences in socioeconomic status, school size, curriculum, and school arrangement. Stedman (1994) in his review of the literature, suggested that future studies can benefit from a national database such as the National Educational Longitudinal Study. Data for this study were obtained from the Nation-al Educational Longitudinal Study of 1988 (NELS:88), sponsored by the National Center for Educational Statistics (NCES, 1990a). NELS:88 is the third and the most recent series of longitudinal studies designed to provide timely information on trends in academic achievement.

The sample of this study consisted of 13,837 White American, 472 Asian immigrant, and 184 Asian American 10th-grade students. Asian immigrant sample was comprised of those whose native language is Not English, whereas Asian American group is comprised of those whose native language is English. The NELS:88 base year sampling procedure was carefully designed and implemented to ensure a nationally representative sample of schools and students. To accomplish the needed representative sample, a twostage probability design was used. For the first stage, a stratified sampling of 1,734 public and private schools was selected, of which 1,052 schools participated. The second stage included random samples of $25( \pm 1)$ students per sampled school, resulting in participation by 24,599 eighth-grade students. Of the 24,599 students, 20,706 were retained in the first follow-up (when students were in the 10th-grade). The school sample was stratified by size, urban vs. rural, regional, and percent minority population. Samples were weighted to compensate for unequal probabilities of selection and to adjust for nonresponse rates. Asian-American students were over-sampled in order to ensure adequate sample sizes for subgroup analyses. The Asian-American sample selected for this study was persons whose countries of origin were China, Japan, Korea, Taiwan, Hong Kong, and other East Asia countries excluding West Asian, South Asian, and Pacific Islander regions. The detailed sampling procedure is described in the National Center for Educational Statistics publications (1990b, 1992).

\section{Instruments}

Students who participated in the NELS:88 completed a 45-minute self-administered questionnaire in their classrooms. The questionnaire was designed to collect information about a wide range of topics, including students' and parents' backgrounds, perception of self, students' educational and vocational activities, post-graduation plans, and aspirations. Students also completed an 85-minute battery of cognitive tests (reading, mathematics, science, and social studies). The variables selected for this study included academic achievement, socioeconomic status, non-school activities, home-work, perceived parental educational expectation, and parental educational involvement.

Academic achievement (ACH). Academic Achievement was measured by a composite score of two cognitive tests developed by Educational Testing Service (mathematics [ 40 items] and reading [21 items]). The reading test consisted of five short passages followed by comprehension and interpretation 
questions. The mathematics test consisted of quantitative comparisons and other questions. A standardized composite score $(M=50, S D=10)$ was used.

Coefficient alpha reliabilities on the eighth-grade sample for the math and reading tests were .90 and .84 respectively. Based on the Mantel-Haenszel odds-ratio analyses (Holland \& Thayer, 1986), there was little evidence of differential item functioning for either gender or racial/ethnic group. Factor analytic results supported the discriminant validity of the three content areas. Convergent validity also was indicated on the hypothesized factors. More detailed psychometric information can be found in the NCES's (1991) Psychometric Report for the NELS:88 Base Year Test Battery.

Socioeconomic status (SES). SES is a composite score that was based on parent's education, occupation, and family income. Parental education ranged from 1 (did not finish high school) to 6 (Ph.D., M.D., or other post graduate degree). Occupational data were coded using the Duncan SEI scale. Family income data were based on the total family income in 1987. Income level ranged from 1 (none) to 15 (\$200,000 or more). Each component was standardized with a mean of 0 and a standard deviation of 1 . All components were averaged yielding the SES composite. The composite scores were then recoded into quartiles (see NCES, 1990a).

Non-school activities. This variable was measured by the following survey questions:

1. In a typical week, how much total time do you spend on all school-sponsored extracurricular activities? Response options and coding are none (0), less than an hour (1), 1-4 hours (2), 5-9 hours (3), 10-19 (4), 20 hours or more (5).

2. How much additional reading do you do each week on your own outside of school-not in connection with school work? Response options and coding are none (0), 1 hour or less (1), 2 hours (2), 3 hours (3), 4-5 hours (4), 6-7 hours (5), 8-9 hours (6), 10 or more hours (7).

3. During the school year, how many hours a day do you usually watch TV or video tapes on weekdays? Response options and coding are none (0), less than one hour (1), 1-2 hours (2), 2-3 hours (3), 3-4 hours (4), 4-5 hours (5), over 5 hours (6).

4. How often do you spend time attending religious activities? Response options and coding are rarely or never (1), less than once a week (2), once or twice (3), every day (4).

Homework (HW). This variable was measured by the survey question: "Overall, about how much time do you spend on homework each week outside of school?" Responses and coding were none (0), 1 hour or less (1), 2-3 hours (2), 4-6 hours (3), 7-9 hours (4), 10-12 hours (5), 13-15 hours (6), over 15 hours (7).

Perceived parental educational expectations (PE). This variable was measured by the sur-vey question: "How far in school do you think your father and your mother want you to get?" Responses were coded from 1 to 6 as follows: (1) "won't finish high school," (2) "will graduate from high school," (3) "will go to vocational school," (4) "will attend college," (5) "will graduate from college," and (6) "will attend a higher level of school after graduating from college." Students recorded their perceptions for each parent separately. A total score was used.

Parental involvement (PI). This variable was measured by three survey questions:

1. "How often do your parents do the following?" Responses were Check on whether you have done your homework, Help you with your homework, Give you special privileges be-cause of good grades, Limit privileges because of poor grades, Require you to do work or chores around the house, Limit the amount of time you can spend watching TV or playing video games, Limit the amount of time you go out with friends on school nights.

2. "In the first half of the school year, how often have you discussed the following with either or both your parents or guardians?" Responses were Selecting course or program at school, School 
activities or events of particular interest to you, Things you have studied in class, Your grades, Plans and preparation for the ACT or SAT tests, Going to college.

3. "In the first half of the school year, how often did either of your parents or guardians do any of the following?" Responses were Attend a school meeting, Attend a school event in which you participated, Act as a volunteer at your school.

\section{Results}

Factor analyses were first conducted to cluster parental involvement survey items. Results indicated a four-factor solution and were labeled as helping, controlling, supporting, and participating. Specific items clustered under each factor can be seen in Table 1. Scale scores were then computed for each factor. Group differences in parental involvement and school activities were first analyzed using MANOVAs. Significant MANOVAs were further analyzed using ANOVAs with Scheffe follow-up procedures.

MANOVAs resulted in significant group differences in Non-School Activities, $F(8,16800)=4.9, p<$ .00001 , and parental involvement, $F(8,24058)=23.2, p<.00001)$. Univariate f-tests indicated significant differences in extra-curricular activities, $F(2,8403)=4.2, p<.01$, religious activities, $F(2,8403)=13.9, p<$ .0001 , parental involvement-helping, $F(2,12565)=7.5, p<.0001$; parental involvement-controlling, $F(2$, $12545)=4.2, p<.01$; and parental involvement-participating, $F(2,12144)=77.5, p<.0001$. Univariate analyses also indicated significant differences in academic proficiency, $F(2,12947)=27.9, p<.0001$; socioeconomic status, $F(2,13591)=21.6, p<.0001$; and perceived parental expectation, $F(2,10875)=$ $59.2, \mathrm{p}<.00001$.

Table 1

Means of Parental Involvement by Groups

\begin{tabular}{|c|c|c|c|c|}
\hline Survey questions & $\begin{array}{l}\text { Asian(R) } \\
\text { immigrant } \\
(n=472)\end{array}$ & $\begin{array}{l}\text { Asian(A) } \\
\text { American } \\
(n=184)\end{array}$ & $\begin{array}{c}\text { White(W) } \\
\text { Americans } \\
(n=13,837)\end{array}$ & $\begin{array}{l}\text { Scheffe } \\
\text { Contrast }\end{array}$ \\
\hline \multicolumn{5}{|l|}{ Helping } \\
\hline Check on your homework & 2.5 & 2.7 & 2.6 & n.s. \\
\hline Help with your homework & 2.0 & 2.0 & 2.4 & $\mathrm{~W}>\mathrm{R}, \mathrm{A}$ \\
\hline Give privileges because of good grades & 2.6 & 2.6 & 2.6 & n.s. \\
\hline \multicolumn{5}{|l|}{ Controlling } \\
\hline Limit privileges because of poor grades & 2.3 & 2.3 & 2.3 & n.s. \\
\hline Require work or chores at home & 3.1 & 3.3 & 3.2 & $\mathrm{~W}>\mathrm{R}$ \\
\hline Limit time watching TV or video games & 2.4 & 2.4 & 2.0 & $\mathrm{R}, \mathrm{A}>\mathrm{W}$ \\
\hline Limit time out with friends on school nights & 2.8 & 2.9 & 2.9 & n.s. \\
\hline \multicolumn{5}{|l|}{ Supporting } \\
\hline Selecting courses or programs at school & 1.9 & 2.0 & 2.0 & $\mathrm{~W}>\mathrm{R}$ \\
\hline School activities/events of interest to you & 1.9 & 2.0 & 2.1 & $\mathrm{~W}>\mathrm{R}$ \\
\hline Things you've studied in class & 1.8 & 1.9 & 2.0 & $\mathrm{~W}>\mathrm{R}, \mathrm{A}$ \\
\hline Your grades & 2.3 & 2.4 & 2.4 & $\mathrm{~W}>\mathrm{R}$ \\
\hline Plans and preparation for ACT or SAT test & 1.8 & 1.7 & 1.5 & $\mathrm{R}, \mathrm{A}>\mathrm{W}$ \\
\hline Going to college & 2.4 & 2.4 & 2.2 & $\mathrm{R}, \mathrm{A}>\mathrm{W}$ \\
\hline \multicolumn{5}{|l|}{ Participating } \\
\hline Attend a school meeting & 0.4 & 0.5 & 0.7 & $\mathrm{~W}>\mathrm{R}, \mathrm{A}$ \\
\hline Attend a school event in which you participated & 0.5 & 0.7 & 1.0 & $\mathrm{~W}>\mathrm{R}, \mathrm{A}$ \\
\hline Act as a volunteer at your school & 0.2 & 0.2 & 0.4 & $\mathrm{~W}>\mathrm{R}, \mathrm{A}$ \\
\hline
\end{tabular}

Note. The responses for Helping and Controlling scales were based on Never (1), Rarely (2), Sometimes (3), Often (4). The responses for the Supporting scale was based on Never (1), Sometimes (2) and Often (3). The responses for Participating scale was based on Never (0), Once or Twice (1), and More than Twice (2). 
Table 2 summarized the results of Scheffe follow-up tests. All variables except time spent on watching TV, non-school related reading, and parental involvement-supporting were found significant between the three groups. Asian American students scored higher than Asian immigrant students, and both Asian American and Asian immigrant students scored higher than White American students on current academic proficiency. Both Asian and White American students attended religious activities more often than Asian immigrant students. White American students spent more time than Asian immigrant students on extracurricular activities and doing homework at school, while both Asian American and Asian immigrant students spent more time doing homework at home. Both Asian American and Asian immigrant students perceived higher parental educational expectation than White American students. For parental involvement, White American students reported more academic help from their parents than did Asian immigrant students. White American students also indicated more parental school participation than both Asian American and Asian immigrant students.

Table 3 provides a summary of regression analyses. Since the primary interest is to investigate the predictors among selected cultural variables, SES was entered first in the regression analyses as a control variable. Non-school activities (time spent on non-school reading, TV, religious activities, and extracurricular activities), homework outside school, perceived parental expectation, and parental involvement (helping, controlling, supporting, participating) were entered in a stepwise manner. Percent variance accounted for current achievement by all variables was $30 \%$ for recent Asian immigrants, $16 \%$ for Asian Americans, and $30 \%$ for White Americans.

Simple correlations, which can be seen in the Table 3 , indicated that socioeconomic status, homework, and perceived educational expectation are positively associated with academic achievement regardless of group memberships. Simple correlations also indicated that watching TV and playing video games were negatively related to academic achievement. Although being involved in religious and extracurricular activities tended to be positively associated with the academic achievement of Asian immigrant and White American students, they were insignificant for Asian American students. Helping and controlling types of parental involvement were somewhat negatively associated with achievement, regardless of racial/ethnic groups.

Table 2

Means and Standard Deviations of Independent Variables by Groups

\begin{tabular}{|c|c|c|c|c|c|c|c|c|}
\hline \multirow[b]{2}{*}{ Variables } & \multicolumn{2}{|c|}{$\begin{array}{c}\text { Asian } \\
\text { immigrant (R) }\end{array}$} & \multicolumn{2}{|c|}{$\begin{array}{c}\text { Asian } \\
\text { American (A) }\end{array}$} & \multicolumn{2}{|c|}{$\begin{array}{c}\text { White } \\
\text { American (W) }\end{array}$} & \multirow[b]{2}{*}{$F$} & \multirow{2}{*}{$\begin{array}{l}\text { Scheffe } \\
\text { Contrast }\end{array}$} \\
\hline & $M$ & $S D$ & $M$ & $S D$ & $M$ & $S D$ & & \\
\hline Academic proficiency & 2.9 & 1.0 & 3.3 & .9 & 2.7 & 1.1 & $27.9^{* * *}$ & $\mathrm{~A}>\mathrm{R}>\mathrm{W}$ \\
\hline Socioeconomic status & .0 & .9 & .4 & .8 & .1 & .8 & $21.6^{* * *}$ & $\mathrm{~A}>\mathrm{W}>\mathrm{R}$ \\
\hline \multicolumn{9}{|l|}{ Time spend on } \\
\hline Religious activities & 1.6 & .9 & 2.0 & .9 & 1.8 & .9 & $13.9^{* * *}$ & $\mathrm{~A}, \mathrm{~W}>\mathrm{R}$ \\
\hline TV and video games & 2.0 & .7 & 2.1 & .8 & 2.1 & .7 & 2.0 & \\
\hline Extra-curricular & 1.4 & 1.4 & 1.7 & 1.4 & 1.6 & 1.5 & $4.2^{*}$ & $\mathrm{~W}>\mathrm{R}$ \\
\hline Non-school reading & 2.1 & 1.7 & 1.9 & 1.6 & 2.0 & 1.8 & 1.0 & \\
\hline Homework & 3.6 & 2.0 & 3.4 & 2.0 & 2.6 & 1.8 & $95.3^{* * *}$ & $\mathrm{~A}, \mathrm{R}>\mathrm{W}$ \\
\hline Parental expectation & 12.3 & 2.0 & 12.6 & 1.5 & 11.2 & 2.6 & $59.2^{* * * *}$ & $\mathrm{~A}, \mathrm{R}>\mathrm{W}$ \\
\hline \multicolumn{9}{|l|}{ Parental involvement } \\
\hline Helping & 7.1 & 2.3 & 7.3 & 2.2 & 7.5 & 2.3 & $7.5^{* * *}$ & $\mathrm{~W}>\mathrm{R}$ \\
\hline Controlling & 10.6 & 2.9 & 10.8 & 2.6 & 10.3 & 2.7 & $4.2^{*}$ & $\mathrm{~A}>\mathrm{W}$ \\
\hline Supporting & 12.1 & 3.0 & 12.3 & 2.5 & 12.3 & 2.7 & 1.6 & \\
\hline Participating & 1.0 & 1.3 & 1.4 & 1.4 & 2.0 & 1.7 & $77.5^{* * * *}$ & $\mathrm{~W}>\mathrm{A}, \mathrm{R}$ \\
\hline
\end{tabular}




\begin{tabular}{|c|c|c|c|c|c|c|c|c|c|c|c|c|}
\hline \multirow[b]{2}{*}{ Variables } & \multicolumn{4}{|c|}{ Asian immigrant } & \multicolumn{4}{|c|}{ Asian American } & \multicolumn{4}{|c|}{ White American } \\
\hline & Step $^{a}$ & $r^{\mathrm{b}}$ & $R^{c}$ & Beta & Step & $r$ & $R$ & $\overline{\text { Beta }}$ & Step & $r$ & $R$ & Beta \\
\hline Socioeconomic status & (1) & .42 & .17 & .32 & (1) & .32 & .09 & .29 & (1) & .38 & .14 & .21 \\
\hline \multicolumn{13}{|l|}{ Non-school activities } \\
\hline Non-school related reading & & .14 & & & & .03 & & & (4) & .19 & .27 & .12 \\
\hline TV and video games & & -.03 & & & & -.16 & & & (8) & -.13 & .30 & -.03 \\
\hline Religious activities & & .18 & & & & -.01 & & & (7) & .16 & .30 & .07 \\
\hline Extracurricular activities & & .15 & & & & -.04 & & & (6) & .22 & .29 & .07 \\
\hline Homework & (2) & .35 & .24 & .27 & (3) & .25 & .16 & .21 & (3) & .30 & .25 & .15 \\
\hline Perceived expectation & (4) & .34 & .30 & .17 & & .22 & & & (2) & .42 & .23 & .26 \\
\hline \multicolumn{13}{|l|}{ Parental involvement } \\
\hline Helping & (3) & -.15 & .28 & -.21 & & -.09 & & & (5) & -.05 & .28 & -.12 \\
\hline Controlling & & -.01 & & & & -.06 & & & & -.01 & & \\
\hline Supporting & & .00 & & & & -.07 & & & (10) & .15 & .30 & -.03 \\
\hline Participating & & .04 & & & (2) & -.21 & .13 & -.23 & (9) & .20 & .30 & .04 \\
\hline
\end{tabular}

The relationship between the supporting type of parental involvement and achievement was positive for White American students $(r=.15)$, but was either insignificant for Asian immigrant students $(r=.00)$ or negative for Asian American students $(r=-.07)$. While the participating type of parental involvement was positively correlated with achievement for White American students $(r=.20)$, it was negatively associated with the achievement of Asian American students (-.21).

The standardized Beta weights $(\beta)$ were used to determine the relative importance of the predictors within each group. For the Asian immigrant group, significant predictors with the order of contribution are socioeconomic status $(\beta=.32)$, homework $(\beta=.27)$, parental involvement-helping $(\beta=$ -.21), and perceived parental expectation $(\beta=.17)$. For the Asian American group, socioeconomic status $(\beta=.29)$, parental-involvement-participating $(\beta=-.23)$, and homework $(\beta=.21)$. For the White American group, perceived parental expectation $(\beta=.26)$, socioeconomic status $(\beta=.21)$, homework $(\beta=.15)$, nonschool reading $(\beta=.12)$, parental involvement-helping $(\beta=-.12)$, religious activities $(\beta=.07)$, extracurricular activities $(\beta=.07)$, parental-involvement-participating $(\beta=.04)$, watching TV and playing video games (? ? .03), and parental involvement-supporting $(\beta=-.03)$.

\section{Discussion}

This study investigated the cultural variations in academic effort, perceived parental expectation, and parental involvement among Asian immigrant, American-born Asian American, and White American students, and how these cultural variations related to academic achievement.

Research has consistently shown that Asian students spend considerably more time in academic related activities than American students. Results of this study indicated that both Asian immigrant and Asian American students spent significantly more time on homework than did White American students. The present study showed that the value of hard work was present in the families of early Asian immigrants, and was well preserved in the families of more established Asian Americans.

Consistent with the previous studies (Mau, 1995, Peng \& Hill, 1995; Stevenson, 1992), the present study also showed that Asian American students perceived significantly higher parental educational expectation than their White American counterparts. Unexpectedly, Asian immigrants and Asian American students did not differ significantly in perceived parental expectation, even though Asian American students are expected to be more assimilated into the White American cultural norm.

There is some evidence that parental involvement (e.g., involved in their children's school work, providing structure and setting limits when necessary, etc.) is empirically linked to students' academic performance, though the specific label and definition of parental involvement variables have varied across 
studies. This study categorized parental involvement into four different aspects, namely helping, controlling, supporting, and participating.

Unlike the prevalent belief that parental involvement is positively associated with students' educational outcomes, the results of this study indicated a more complex relationship. The link between parental involvement and academic achievement appeared to be a function of the type of parental involvement. Contrary to findings from other studies, this study suggested that, regardless of culture groups, the more helping and controlling parents were in their children's school work, e.g., checking on and helping with homework, providing structure and setting limits for non-academic activities, the less likely their children were to perform well. It is likely that those parents whose children did well academically tended not to get involved with their children's school work. It is also likely that they do not know how to get involved effectively since parental involvement with schools may not be familiar from their own cultural background. It should be also noted that English played a significant factor in parental involvement. Parents with limited English proficiency are least likely to help their children with schoolwork or participate in the school activities.

Age may also be a factor for these inconsistent findings. Earlier studies (Buxton, 1973; Chen \& Stevenson, 1989) have indicated that students' age was negatively related to parental support for schoolwork. Although young children may gain much from parental educational input, high school students typically are at a developmental stage in which they are striving for independence. The relationship between parental involvement and school achievement may largely depend on age, and parental perception of children's school performance. A further investigation on this matter is needed.

Regarding the supporting and participating types of parental involvement, the results also indicated a complicated relationship. Interestingly, the present study suggested that the more parents participated in school events, meetings, or acted as a volunteer, the less likely that Asian American students were to perform well, but the more likely White American students were to perform well. Similar, but less clear relationships were found for the supporting aspect of parental involvement among groups. One should be cautious in making a causal interpretation of these findings as low academic performance is not necessarily a result of high parental participation and support, and vice versa.

In examining the between group differences in the degree of overall parental involvement, some patterns emerge. Results indicated differences in helping, supporting, and participating types of parental involvement with Asian immigrant parents as the least involved, White American parents as the most involved, and Asian American parents in between. It is likely that the acculturation process plays a significant role in difference among groups. Parents of recent immigrants typically are less fluent in English and have little knowledge about the school environment, which may limit their school involvement. However, it is also likely that parents of Asian immigrant students may perceive school involvement as less important due to cultural beliefs. The fact that any type of parental involvement either had no relationship or a negative relationship with students' academic performance for Asian students lends support to the lack of involvement of Asian parents. In contrast, supporting and participating types of parental involvement had positive relationships with academic achievement for White American students. Also possibly due to cultural beliefs, but in a different pattern, both Asian immigrant and Asian American students reported more parental control and restriction in non-school activities than their White American counterparts.

Parental involvement, in general, was not as predictive as homework and parental expectation. The helping type of parental involvement appeared to be a negative predictor for both Asian immigrant and White American students. The participating type of parental involvement was also a negative predictor for Asian Americans but a positive predictor for White Americans. The different prediction outcomes for Asian and White American students in participating is somewhat difficult to interpret. Further investigations may gain insight to the inverse predictive relationship between participation and achievement outcomes for Asian American students. 
Non-school related activities were significant predictors for Asian immigrant and Asian American students, and were the least significant predictors for White American students. Variance ac-counted for academic achievement was not equal in size among groups. The percent of variance ac-counted for academic achievement by the selected predictors was greater for Asian immigrant and White American students than for the Asian American students.

In summary, the academic success of Asian students regardless of new or established immigrants seems to be associated with high parental educational expectation and educational effort. While parental involvement may be important for White students, it is generally not predictive of Asian students' educational achievement. Riley (1993) suggested that, regardless of background or economic status, higher academic expectations for all students are needed. Instead of giving up on lower achieving students because of their disadvantaged status, we must recognize students' potential. It is suggested that schools should set higher expectations, encourage students to persist in school work, and cooperate with parents to instill functional values within children.

While the findings of this study cannot draw a causal relationship between parental involvement and academic achievement, it does highlight the importance of examining this relationship further. At a minimum, educators and school administrators should be aware of the differential prediction of parental involvement variables, as encouraging parental participation may not have the same educational outcomes for Asian American students as for White American students.

\section{References}

American College Testing. (1989). The high school profile report, normative data, high school class of 1989. lowa City, IA: Author.

Atkinson, D. R. (1983). Ethnic similarity in counseling psychology: A review of research. The Counseling Psychology, 11, 79-92.

Baker, D. P. (1993). Compared to Japan, the U.S. is a low achiever . . really: New evidence and comment on Westbury. Educational Researcher, 22(3), 18-20.

Beardsley, T. (1992, October). Teaching real science. Scientific American, 267, 98-108.

Buxton, C. (1973). Adolescent in school. New Haven, CT: Yale University Press.

Chang, C. (1985). Family influences on school achievement in China. U.S.-China Friendship, 9(4), 20.

Chen, C., \& Stevenson, H. W. (1989). Homework: A cross-cultural examination. Child Development, 60, 551-561. Cipra, B. (1993, January 1). An awesome look at Japan's Math SAT. Science, 259, 22.

College Board. (1989). College-bound seniors: 1989 SAT profile. New York: College Entrance Examination Board. Cuellar, I., Harris, L. C., \& Jasso, R. (1980). An acculturation scale for Mexican American normal and clinical populations. Hispanic Journal of Behavior Sciences, 2, 199-217.

Epstein, J. L. (1985). Home and school connections in schools of future: Implications of research on parental involvement. Peabody Journal of Education, 62, 18-41.

Fong, S. L. M. (1973). Assimilation and changing social roles of Chinese American. Journal of Social Issues, 29(2), 115-127.

Green, P. J., Dugoni, B. L., Ingels, S. J., \& Camburn, E. (1995). A profile of the American high school senior in 1992. Washington DC: U.S. Department of Education.

Hess, R. D., \& Holloway, S. D. (1984). Family and school as educational institutions. In R. D. Parke (Ed.), Review of child development research, Vol. 7: The family (pp. 179-222). Chicago: University of Chicago Press.

Hess, R. D., Chang, C-M., \& McDevitt, T. M. (1987). Cultural variations in family belief about children's performance in mathematics: Comparisons among People's Republic of China, Chinese American, and Caucasian-American families. Journal of Educational Psychology, 79, 179-188.

Hewison, J., \& Tizard, J. (1980). Parental involvement and reading attainment. British Journal of Educational Psychology, 50, 209-215. 
Holland, P. W., \& Thayer, D. T. (1986). Differential item functioning and the Mantel-Haenszel procedure. ETS Research Report No. 86-31. Princeton, NJ.

Kerckhoff, A. C. (1989). On the social psychology of social mobility processes. Social Forces, 68, 17-25.

Mau, W. C. (1995). Educational planning and academic achievement of middle school students: A racial/cultural comparisons. Journal of Counseling and Development, 73, 518-526.

Mayer, R. E., \& Tajika, H. (1993). Conducting and comprehending cross-cultural comparison: Reply to Stigler and Miller (1993). Journal of Educational Psychology, 85, 560-565.

Mayer, R. E., Tajika, H., \& Stanley, C. (1991). Mathematical problem solving in Japan and the United States: A controlled comparison. Journal of Educational Psychology, 83, 69-72.

National Center for Educational Statistics. (1990a). National education longitudinal study of 1988, base year: Student component data file user's manual (Report No. 90-464). Washington, DC: U.S. Department of Education.

National Center for Educational Statistics. (1990b). National education longitudinal study of 1988: Base year sample design report (Report No. 90-463). Washington, DC: U.S. Department of Education.

National Center for Educational Statistics. (1991). Psychometric report for the NELS:88: Base year test battery (Report No. 91-468). Washington, DC: U.S. Department of Education.

National Center for Educational Statistics. (1992). National education longitudinal study of 1988: First follow-up: Student component data file User's manual (Report No. 92-030). Washington, DC: U.S. Department of Education.

Peng, S. S., \& Hill, S. T. (1995). Understanding racial-ethnic differences in secondary school science and mathematics achievement. Washington, DC: U.S. Department of Education.

Riley, R. W. (1993, May 17). Strong effort needed to upgrade education. Special to the Baltimore Sun. Wichita Eagle (p. 13A). Wichita, KS.

Scott-Jones, D. (1984). Family influences on cognitive development and school achievement. In E. W. Gordon (Ed.), Review of research in education, (Vol. 11, 259-304). Washington, DC: American Educational Research Association.

Smith, T. E. (1991). Agreement of adolescent educational expectations with perceived maternal and paternal educational goals. Youth and Society, 23, 155-174.

Social Science Research Council Summer Seminar on Acculturation. (1954). Acculturation: An exploratory formulation. American Anthropologist, 56, 973-1002.

Sodowsky, G. R., Lai, E. W. M., \& Plake, B. (1991). Moderating effects of sociocultural variables on acculturation attitudes of Hispanic and Asian Americans. Journal of Counseling and Development.

Stedman, L. C. (1994). Incomplete explanations: The case of U.S. performance in the international assessment of education. Educational Researcher, 23(7), 24-32.

Stevenson, H. W. (1992, December). Learning from Asian schools. Scientific American, 267, 70-76.

Stevenson, H. W., \& Stigler, J. W. (1992). The learning gap. New York: Summit Books.

Stevenson, H. W., Chen, C., \& Lee, S-Y. (1993, January 1). Mathematics achievement of Chinese, Japanese and American Children: Ten years later. Science, 259, 53-58.

Stevenson, H. W., Lee, S., \& Stigler, J. W. (1986). Mathematics achievement of Chinese, Japanese and American Children. Science, 231, 693-699.

Stigler, J. W., \& Miller, K. F. (1993). A good match is hard to find: Comment on Mayer, Tajika, and Stanley (1991). Journal of Educational Psychology, 85, 554-559.

Sue, S., \& Okazaki, S. (1990). Asian-American educational achievements: A phenomenon in search of an explanation. American Psychologist, 45, 913-920.

Westbury, I. (1992). Comparing American and Japanese achievement: Is the United States really a low achiever? Educational Researcher, 21(5), 18-24.

Westbury, I. (1993). American and Japanese achievement . . . again: A response to Baker. Educational Researcher, 22(3), 21-25. 
Yan, W-F., \& Gaier, E. L. (1994). Causal attributions for college success and failure: An Asian-American comparison. Journal of Cross-Cultural Psychology, 25, 146-158. 